\title{
Vigilância e relações de poder nas redes sociais: questões éticas na sociedade contemporânea
}

Surveillance and relations of power in social networks: ethical issues in contemporary society

Vigilancia y relaciones de poder en las redes sociales: cuestiones éticas en la sociedad contemporánea

Fábio Medeiros da Rosa

- Doutorando em Administração de Empresas pelo Instituto Coppead da Universidade Federal do Rio de Janeiro (UFRJ)

- Mestre em Gestão Empresarial pela Escola Brasileira de Administração Pública e de Empresas da Fundação Getúlio Vargas (Ebape-FGV)

- Diretor associado da Agência Brasileira de Agentes Digitais do Rio de Janeiro (Abradi-RJ)

- Professor convidado de Marketing Digital e Comunicação em cursos de pós-graduação lato sensu

- Professor em cursos de MBA executivo e Analista da FGV

- Membro do comitê de assessoramento da agência de fomento Inovativa Brasil

- E-mail: fabio@agenciamulticom.com.br

Leandro Chevitarese

- $\quad$ Doutor em Filosofia pela Pontifícia Universidade Católica do Rio de Janeiro (PUC-Rio)

- Mestre em Psicossociologia de Comunidade e Ecologia Social pela Universidade Federal do Rio de Janeiro (UFRJ)

- Mestre em Filosofia pela PUC-Rio

- Professor adjunto do Departamento de Educação e Sociedade do Instituto Multidisciplinar da Universidade Federal Rural do Rio de Janeiro (IM-UFRRJ)

- Professor do Programa de Pós-Graduação em Filosofia (PPGFIL) da UFRRJ

- Professor convidado do doutorado no Coppead da UFRJ

- E-mail: leandrochevitarese@yahoo.com.br 


\section{Resumo}

Neste artigo, discutimos as redes sociais enquanto meio de comunicação contemporânea, apresentando uma leitura filosófica desse fenômeno social, considerando o problema da liberdade na atual sociedade tecnológica. Os caminhos metodológicos passam por descrever as redes sociais, em especial o Facebook e o Snapchat, como pano de fundo para a formulação de desafios éticos, envolvendo a problemática dos mecanismos de poder e vigilância, bem como seus efeitos de produção de subjetividade na sociedade e nas organizações.

\section{PALAVRAS-CHAVE: RELAÇÕES DE PODER • VIGILÂNCIA • REDES SOCIAIS •ÉTICA.}

\section{Abstract}

In this article, we discuss the social networks as means of contemporary communication, presenting a philosophical reading of this social phenomenon, considering the problem of freedom in the current technological society. The methodological procedure goes on to describe the social networks, specially Facebook and Snapchat, as a background to elaborate ethical challenges, involving the problematic of power mechanisms and surveillance, as well as its effects of subjectivity production in the society and the organizations.

KEYWORDS: POWER RELATIONS • SURVEILLANCE・SOCIAL NETWORKING • ETHICS.

\section{Resumen}

En este artículo, discutimos las redes sociales como medio de comunicación contemporánea, presentándose una lectura filosófica de ese fenómeno social, considerándose el problema de la libertad en la actual sociedad tecnológica. Los caminos metodológicos pasan por describir las redes sociales, especialmente Facebook y Snapchat, como telón de fondo para la formulación de desafíos éticos, involucrando la problemática de los mecanismos de poder y vigilancia, bien como sus efectos de producción de subjetividad en la sociedad y en las organizaciones. 
ivemos em uma sociedade em rede (Castells, 1999), em que projetamos nas redes sociais nossa imagem de acordo com o que queremos assumir em determinados contextos virtuais (Belk, 2013). Criamos assim um processo de afiliação e formação da identidade por meio das comunidades virtuais (Kozinets, 2001).

Esse fenômeno imagético e identitário se manifesta não só na esfera pessoal e social, mas também organizacional. Portanto, está presente nas práticas de Relações Públicas das empresas (Kunsch, 2004; 2006a; 2006b) e na interação com seus públicos distintos. Assim, é fundamental discutir o fenômeno ético do ponto vista organizacional, entendendo seus desdobramentos acadêmicos e profissionais na área de comunicação social.

0 advento da internet trouxe mudanças significativas na nossa sociedade. A web 2.0 alterou a forma como as pessoas e instituições utilizam a rede digital. Essa nova tecnologia trouxe interatividade no processo e na comunicação: tanto na dinâmica interpessoal como na relação com as marcas. 0 fluxo de informação passou a ser bidirecional, criando um espaço para expressão e exposição de conteúdo (Belk, 2014).

Como maior representante dessa nova forma de comunicação, um dos eleitos deste artigo como fenômeno de rede social a ser analisado foi o Facebook. A escolha se deu por relevância', pois a rede social é a que concentra mais usuários no mundo (Vianna, 2017).

Além do Facebook, outra rede social analisada é o Snapchat ${ }^{2}$. Essa escolha se deu por contraste de utilização e natureza distinta de uso em comparação ao Facebook. Se por um lado os usuários empregam o Facebook como verdadeiros diários pessoais, por outro, o Snapchat surge como alternativa a este comportamento digital, uma vez que o conteúdo postado desaparece ${ }^{3}$ após ser visualizado, tendo um ciclo de vida muito curto nas postagens.

Com isso, pretendemos analisar a relação do uso das redes sociais e os mecanismos de vigilância social que tensionam as publicações e as interações dos usuários nas redes. A abordagem pretende investigar aspectos ligados aos mecanismos de controle e a produção de subjetividade em sua articulação com questões éticas que se fazem presentes nesse cenário. Trata-se aqui de promover um olhar filosófico sobre um dos fenômenos mais expressivos e disruptivos na nossa sociedade contemporânea: as redes sociais.

\section{INTERAÇÃO NAS REDES SOCIAIS: FACEBOOK E SNAPCHAT}

O Facebook ocupa atualmente o patamar de maior rede social do mundo 4 tendo influências significativas no perfil de navegação dos brasileiros ${ }^{5}$. Ele foi capaz de devolver o poder de escolha de informação ao indivíduo, colocando o usuário no centro das atenções e seus interesses em primeiro lugar. Assim, o Facebook revolucionou a realidade cibernética e trouxe uma forma inédita de estar na sociedade, dando uma nova ênfase à sociedade em rede (Castells, 1999).

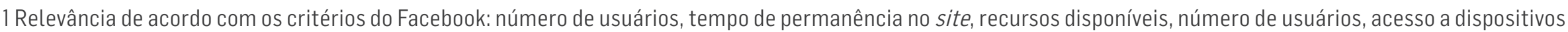
móveis, penetração e capilaridade.

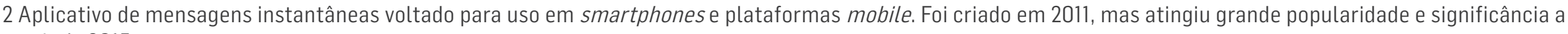
partir de 2015.

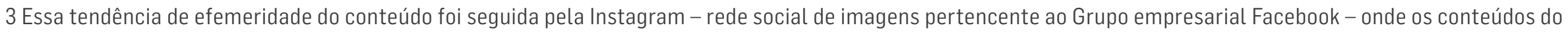
Stories (compartilhamento de momentos com fotos e vídeos personalizados) desaparecem automaticamente 24 horas após postagem original.

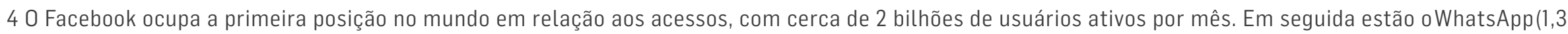
bilhão),Messenger(1,2 bilhão),WeChat (938 milhões) elnstagram(700 milhões) completando a lista (Kurtz, 2017).

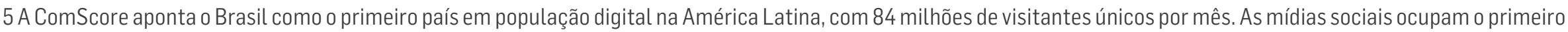

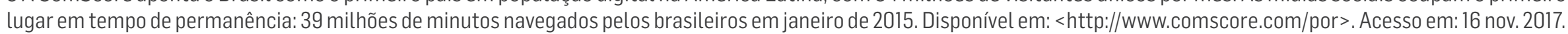


Para Oliveira e Huertas (2014), quando um indivíduo está satisfeito com a sua vida, se torna também mais motivado a usar 0 Facebook. Isso se justifica pela pressão social e pelo sentimento de inclusão e engajamento advindo da participação em uma comunidade virtual. Com isso, o compartilhamento de satisfação pessoal é ampliado e motivado pelos laços sociais e relações entre os indivíduos. Por essa perspectiva, é possível afirmar que o Facebook se torna uma vitrine pessoal e profissional. As pessoas escolhem o que querem mostrar aos demais e que imagem querem projetar nesse ambiente. Existe uma moderação e produção dos fatos em função dos interesses de quem posta algo.

Segundo Tubenchlak et al. (2015), o Facebook permite que os usuários usem identidades verdadeiras e estabeleçam contato com sua rede social de relacionamento: família, amigos e colegas de trabalho. As interações são caracterizadas por relações pessoais mais próximas e colaborativas. Para os autores, a interação entre os participantes da rede influencia a forma como se comunicam, existindo, inclusive, uma preocupação em ajudar a rede de contatos em suas decisões de compra e consumo. Portanto, o engajamento e o boca a boca tornam-se uma das principais esferas de influência na decisão de compra dos usuários, sendo também importantes métricas mercadológicas de muitas empresas.

As mudanças trazidas pelo Facebook se notam não apenas no ambiente doméstico, mas também no empresarial. No caso das organizações, a construção e manutenção da imagem institucional no ambiente digital se torna mais desafiadora, principalmente do ponto de vista da Reputação Digital Corporativa (Terra, 2005), levando significativos desafios para os profissionais de Comunicação, em especial para os profissionais de Relações Públicas.

Além do Facebook, outras redes sociais ganham importância no dia a dia e influenciam os hábitos de consumo e produção de conteúdo dos usuários. 0 fenômeno do Snapchat, apesar de recente, começa a ganhar importância e atenção acadêmica (Bayer et al., 2016; Utz; Muscanell; Khalid, 2015; Vaterlaus et al., 2016).

O uso ao aplicativo se intensifica e ganha cada vez mais adeptos e usuários ${ }^{6}$ a cada dia. Um dos principais usos da plataforma se dá como um instrumento de streaming ao vivo, pelo qual os usuários compartilham suas rotinas com seus amigos e seus seguidores presentes na plataforma?

O Snapchat permite que o usuário envie mensagens de textos, fotos ou vídeos em tempo real. Porém, o grande diferencial do aplicativo é que o conteúdo se apaga depois de ser visualizado, dando certa "liberdade" de uso, trazendo flexibilidade na "netiqueta"8 e na construção da identidade virtual imposta pela sociedade contemporânea.

Além do caráter de volatilidade da informação, o Snapchat apresenta ferramentas interativas, como as Lenses, espécies de filtros interativos e divertidos para fotos e vídeos, que permitem adicionar efeitos exclusivos nas selfies ${ }^{9}$ e filmagens. Uma das principais funcionalidades do aplicativo é a capacidade - e a facilidade - de fazer transmissões ao vivo. Essa funcionalidade é chamada de "Snapchat Live", pela qual pode-se transmitir eventos e cenas do cotidiano ao vivo.

Além de tais funcionalidades, o significativo diferencial do Snapchat é o caráter efêmero, dado ao fato de que as informações "somem" imediatamente após sua audiência. Outro fator de sucesso do aplicativo é a simplicidade de uso. As publicações são feitas através de aparelhos mobiles, dispensando a necessidade de aparatos tecnológicos e infraestruturas complexas de transmissão.

6 Segundo o Snapchat, são 100 milhões de usuários ativos por dia; 700 milhões de usuários cadastrados no mundo; 28 milhões de usuários na América Latina. No Brasil, 6,5\% dos usuários de redes sociais usam o aplicativo; $70 \%$ dos usuários são mulheres e estão na faixa etária entre 13 e 34 anos.

70 aplicativo movimenta cerca de 6 bilhões de visualizações diárias e acumula 200 milhões de "snaps" enviados diariamente. Por isso, as marcas têm lançado mão do Snapchat como uso comercial e mercadológico. 


\section{UMA LEITURA FILOSÓFICA DAS REDES SOCIAIS: O PANOPTISMO E O PROBLEMA DA LIBERDADE EM SUA INTERFACE COM DESAFIOS ÉTICOS}

\section{O panóptico: vigilância, punição e produção de subjetividade}

0 conceito original do panóptico, proposto por Bentham (2003), foi ressignificado por Foucault (2002) como metáfora para explicar a vigilância e os mecanismos de poder presentes não somente em diferentes instituições, como escolas, exército, empresas, família etc., mas também perceptíveis na dinâmica das relações que atravessam o tecido social.

A ideia original de Bentham tratava-se simplesmente de uma construção arquitetônica em formato de anel, em que 0 centro previa uma torre de vigilância. 0 princípio do panóptico é a concentração de visibilidade total dos corpos por meio de mecanismo que instala uma dissociação entre quem vê e quem é visto, somado ao efeito de luz, que faz com que os corpos apareçam mesmo involuntariamente.

Nesse sentido, entende-se que o panóptico tratava primeiramente de uma organização arquitetônica que visava exclusivamente à maximização da vigilância carcerária. Sua amplitude de aplicações elevou seu status arquitetônico para a esfera social, exercendo papel central na leitura foucaultiana da microfísica do poder. Como chave de compreensão da sociedade moderna, ou sociedade disciplinar, o panóptico é concebido como um dispositivo efetivo de poder, uma vez que estabelece uma rede de vigilância e punição envolvendo diversos elementos, tais como: discursos, instituições, construções urbanas/arquitetônicas, leis, regras, medidas administrativas, comportamentos morais etc. Todas essas esferas configuram a vigilância completa dos corpos com implicações econômico-políticas na sociedade. Segundo Foucault (2002), os mecanismos de vigilância articulam-se continuamente a processos de punição, "sanções normalizadoras" que se apresentam como "micropenalidades" que visam a produzir "corpos úteis e dóceis". Ao promover a adequação dos comportamentos, os mecanismos de punição fomentam a produção de subjetividades, ou seja, constroem de modo sutil e duradouro a maneira pela qual percebemos e sentimos subjetivamente a realidade, articulando formas de comportamento correlatas a tal "normalidade".

Segundo Chevitarese e Pedro (2005), Foucault desenvolve uma "genealogia do poder", investigando as condições pelas quais se estabelece uma determinada "verdade" e de que modo tal saber passa a exercer relações de poder, produzindo comportamento e vida social, construindo formas de subjetividade nas relações. A este poder de produzir e gerir a vida, Foucault chamou de biopoder, identificando que seu modo de atuação na sociedade moderna depende fundamentalmente daquilo que ele denominou disciplinas. Tais métodos atuam sobre o corpo e "realizam a sujeição constante de suas forças e thes impõem uma relação de docilidade-utilidade" (Foucault, 2002, p. 118). Segundo o autor, o biopoder (Foucault, 1988) organiza-se em grande parte articuladamente às instituições modernas, tais como a escola, a fábrica, o hospital, a família e a prisão, tendendo a promover um conjunto de regularidades e padrões de comportamento pertencentes a uma coletividade ou determinada população.

Nesse contexto, pode-se visualizar aquilo que Foucault descrevia em relação à dinâmica social: o poder não está simplesmente localizado em uma instituição, nos aparelhos estatais ou no governo instituído, as relações de poder são exercidas na dinâmica cotidiana e atravessam o tecido social.

O poder deve ser analisado como uma coisa que circula, ou melhor, como uma coisa que só funciona em cadeia. Jamais ele está localizado aqui ou ali, jamais está entre nas mãos de alguns, jamais e apossado como uma riqueza ou um bem. 0 poder funciona. O poder se exerce em rede e, nessa rede, não só os indivíduos circulam, mas estão sempre em posição de ser submetidos a esse poder e também de exercê-lo. (Foucault, 1999, p. 35) 
0 poder opera em rede. Os mecanismos de controle e coerção são exercidos e sofridos por nós mesmos, vêm de nossos pares e redes de contato. Neste "fogo amigo", por meio das redes sociais, todos os usuários comuns exercem sua "tarefa" de vigilância sobre os atos dos seus "amigos" virtuais. Vejamos.

\section{O panóptico nas redes sociais: novas configurações virtuais para vigilância, punição e produção de subjetividade}

Gilles Deleuze (1992a;1992b), dando continuidade às análises foucaultianas, descreve alguns aspectos que poderiam distinguir uma sociedade disciplinar de uma sociedade de controle. Na reflexão deleuziana, as sociedades disciplinares se deram num período compreendido entre o século XVIII e a Segunda Guerra mundial. Após esse período, iniciou-se um declínio desse modelo de sociedade e respectiva emergência da sociedade de controle. Segundo Deleuze, uma nova ordem vem substituindo as antigas disciplinas: "estamos entrando nas sociedades de controle, que funcionam não mais por confinamento, mas por controle contínuo e comunicação instantânea" (Deleuze, 1992b, p. 216).

Entende-se que essa submissão é capaz de gerar uma crise generalizada das instituições e em seus instrumentos de confinamento. Segundo Chevitarese e Pedro (2005), a escola deu lugar à instrução; a fábrica deu lugar à empresa; o hospital deu lugar à medicina; a família mudou de rosto, deixou de ser caracterizada pelo núcleo "pai, mãe, filhos", tornou-se convivência familiar; a prisão tende para a liberdade oficialmente vigiada; 0 exército tornou-se profissão militar.

Nesse sentido, pode-se observar dois aspectos fundamentais nessa metamorfose: 1) as fronteiras entre as instituições tornam-se tênues, voláteis, flexíveis; 2) o roteiro disciplinar a ser cumprido torna-se um horizonte, não havendo mais término, mas um constante prolongamento, que se torna possível pelos recursos de comunicação virtual e pelo contexto do capitalismo tardio.

Para Bauman (1999) a metáfora do panóptico de Foucault daria lugar à vigilância dos bancos de dados, operando em uma espécie de "versão ciberespacial" do panóptico original. Na visão baumaniana a vigilância opera sem a necessidade de uma concretização arquitetônica, ela é eletrônica e digital. Essa versão digitalizada do panóptico opera de modo distinto, ainda que possamos considerar complementar a versão foucaultiana, na qual o propósito do panóptico era instituir a disciplina como forma de moldar padrões, evitando variações. Portanto, o objetivo dos bancos de dados é conferir "credibilidade" às pessoas cadastradas, garantindo sua confiabilidade. Para o autor, os bancos de dados têm como principal propósito garantir que ninguém escape do espaço estreitamente vigiado. Da mesma maneira, Baumam atribui aos bancos de dados, a função de garantir que nenhum intruso consiga acesso sem as credenciais adequadas (Chevitarese; Pedro, 2005).

Compreendendo a agência da sociedade de controle, Bauman (1999) sugere que os mecanismos de controle virtuais - por meio do Big Data - geram melhor circulação na web. Quanto mais somos vigiados constantemente através dos poderosos algoritmos do Facebook, ou por quaisquer outros mecanismos similares, mais podemos circular com maior liberdade no ciberespaço. Os logins sociais ${ }^{10}$ e o conteúdo aberto da internet permitem que acessemos uma infinidade de dados e possamos interagir com diferentes pessoas em diferentes lugares. Ao contrário do panóptico, o banco de dados tem relação com a mobilidade, não é feito para imobilizar as pessoas (Bauman, 1999). Para o autor, quanto mais informação sobre você contenha o banco de dados, mas livremente você poderá se movimentar. Nessa lógica, a liberdade de navegação é proporcional ao controle exercido e à vigilância da rede. Trata-se aqui da dinâmica do controle, que opera pela sedução à máxima visibilidade e pela oferta da "liberdade de navegação".

10 É uma forma de acesso usando a informação a partir de um serviço de rede social para fazer login em um site de terceiros em vez de criar uma nova conta de acesso especificamente para esse site. 
A dinâmica dos bancos de dados não retira de cena a ação que é própria ao panóptico, apenas a complementa em outro nível, pois a vigilância e a disciplinarização continuam a operar nas redes sociais. Na sociedade atual, um dos principais panópticos sociais é o Facebook. Estamos sendo vigiados e punidos constantemente por nossos pares e "amigos" nas redes sociais. As métricas de engajamento (curtidas, compartilhamentos, comentários) - e principalmente a falta de interação das postagens - são consequências do julgamento social.

Assim como na sociedade disciplinar os corpos físicos são docilizados, gerando efeitos de subjetivação e normalização, no Facebook agora são os "corpos virtuais" o alvo da vigilância e adequação, pois a subjetividade que se expressa pelo comportamento na rede sofre "micropenalidades" visando sua padronização. 0 cunho e o tom das postagens devem sofrer uma espécie de "ortopedia digital" para serem admirados, conquistarem curtidas, comentários e compartilhamentos, garantindo a elevação da estima virtual. 0 conteúdo postado está subjugado à aprovação social, sob pena de ser ignorado, rechaçado ou sofrer sanções sociais, sejam elas virtuais (expulsão de grupos, rompimento de "amizades no Facebook"), chegando às sanções presenciais (fofocas, exclusão de eventos sociais, discriminação etc.), ou mesmo às sanções legais (processos por calúnia, injúria, difamação etc.).

Para Gomes (2003) as estruturas midiáticas da sociedade transfiguraram-se no panóptico apresentado por Foucault. Nesse sentido, os sistemas de "vigilância" da mídia permitem que a sociedade esteja sendo controlada e acompanhada em seu cotidiano, não necessariamente por instituições formais e governamentais, mas por usuários dentro da própria rede de contatos do indivíduo. Seus "amigos" virtuais.

Partindo da análise iniciada por Foucault, Bauman (2001) lança a ideia de pós-panóptico e de vigilância líquida para explicar a sociedade contemporânea. Para o autor, não há mais um olhar centralizador para nos sentirmos vigiados. Não é mais possível ver claramente os pontos de vigilância. Nesse sentido a vigilância aumenta com o advento das redes sociais, pois somos controlados e vigiados a cada movimento, a cada post, em uma espécie de "vigilância participativa", na qual todos vigiam a todos continuamente. Portanto, o próprio Facebook e seu sistema de armazenagem de dados pode ser entendida como uma fonte inesgotável para a vigilância líquida, uma vez que todo e qualquer rastro de uma pessoa é passível de ser identificado e capturado a qualquer momento nessa rede social. No panóptico social do Facebook, é a própria sociedade que começa a definir seus limites. Isso é visível nos comentários que acompanham as publicações feitas diariamente por seus usuários.

Por outro lado, é interessante observar que o Snapchat oferece outras possibilidades de "liberdade de movimentação", diferentes daquelas aqui observadas por Bauman. Tendo em vista que seu conteúdo é volátil e desaparece rapidamente, há menos informações registradas nos "bancos de dados", minimizando a vigilância e a possibilidade de reações às publicações, o que obviamente enfraquece as relações de poder que são exercidas na rede. Assim, o Snapchat parece oferecer certa "área de sombra" à constante visibilidade que os usuários são submetidos em outras redes sociais. Pelas caraterísticas de "maior liberdade", tendo em vista seu conteúdo efêmero, o Snapchat apresenta a seus usuários uma alterativa ao intenso monitoramento e julgamento social. Nesse sentido, pode-se considerar que toda dinâmica de vigilância e punição, que pode ser muito bem observada na primeira rede apresentada, o Facebook, torna-se muito mais tênue e volátil no Snapchat, ainda que permaneça atuante. É significativo registrar que isso se faz presente pelas características implícitas à mídia. Tal cenário oferece outra configuração para as possibilidades de liberdade ali ofertadas, com diferentes implicações que merecem ser consideradas no cenário contemporâneo.

Se por um lado, no Snapchat há menos vigilância e consequentemente surge certo enfraquecimento das relações de poder e de seus mecanismos de subjetivação e produção de normalidade, oferecendo mais "liberdade de expressão", por outro, tal contexto permite que essa mesma "liberdade" seja veículo para manifestações de maior extremismo político e ideológico, publicações de caráter erótico e sexual, exposições mais significativas da privacidade etc. 0 que reapresenta de modo ainda 
mais contundente o problema da responsabilidade diante do exercício da liberdade, ou seja, nos exige ainda mais a reflexão sobre a eticidade de nossas ações.

Na atualidade, 0 avanço tecnológico tem ampliado as possibilidades de controle e vigilância. As máquinas de vigilância são implantadas em diferentes ambientes. Sem dúvida, não se pode excluir dessa análise o efeito produzido por tal dinâmica nas estruturas organizacionais. Com a progressiva diluição das fronteiras entre o público e o privado, que é própria ao cenário contemporâneo, tudo que se publica na rede - como o próprio nome já diz - é "público". Não importa que seja uma rede social ou que a publicação seja direcionada a "amigos", toda informação tende a circular de modo não arbitrado por qualquer intensão prévia, trazendo repercussões para seus agentes no ambiente organizacional. Não há mais como delimitar uma fronteira entre o virtual e o real, pois tudo que se faz na rede é público e gera consequências sociais e profissionais. Parece implausível supor que se pode agir em um ambiente organizacional de um determinado modo e manifestar-se na rede antagonicamente, em termos de valores e conduta, do mesmo modo que pareceria implausível sustentar uma imagem artificiosa na rede, seja ela qual for, pois o real a desmentiria, cedo ou tarde. Tudo que é publicado, que se curte, que se compartilha ou que se comenta, acaba por configurar uma identidade ao agente que sofrerá aprovação ou reprovação em sua organização dependendo de como sua movimentação oferece acordo ou desacordo com os valores da instituição.

Se, por um lado, isso configura um universo de "micropenalidades" em casos de desvio do comportamento esperado, por outro, não se pode perder de vista que exercemos relações de poder cada vez que nos manifestamos, tensionando padrões de comportamento e subjetividade vigentes na sociedade e nas organizações. A questão que se apresenta nesse cenário é sobre quais seriam as melhores formas de exercício de nossa liberdade nas redes, o que nos remete a necessidade de pensar quais valores fundamentalmente queremos afirmar, ou seja, de enfrentar o desafio de pensar eticamente sobre nosso modo de expressão virtual. Para tanto faz-se necessário frisar aqui o que Foucault denomina uma "ontologia crítica de nós mesmos", investigando de que modo temos nos constituído subjetivamente a partir de nossas relações no espaço virtual. Trata-se de uma "tarefa ética":

É preciso considerar a ontologia crítica de nós mesmos, não certamente como uma teoria, uma doutrina, nem mesmo como um corpo permanente de saber que se acumula; é preciso concebê-la como uma atitude, um êthos, uma via filosófica em que a crítica do que somos é simultaneamente análise histórica dos limites que nos são colocados e prova de sua ultrapassagem possível (Foucault, 2005, p. 351, grifos nossos).

A análise crítica "daquilo no que nos tornamos" é condição de possibilidade para repensar nossas possibilidades de mudança. E compreendendo a ética como uma reflexão filosófica sobre as práticas morais vigentes (Macêdo et al., 2015) pensar eticamente nosso modo de agir nas redes sociais corresponde ao desafio de se perguntar: o que fundamenta racionalmente nossos valores em relação à sociedade? Ou ainda, tendo em vista o tensionamento das relações de poder que sempre se fazem presentes, pelo que vale a pena lutar e resistir?

\section{CONSIDERAÇÕES FINAIS}

A filosofia nos convida a pensar, acima de tudo, sobre o mundo em que vivemos. Nesse sentido, é fundamental refletir sobre o fenômeno das redes sociais, cada vez mais presente em nossa contemporaneidade. Neste artigo tomamos como objeto de análise o Facebook e o Snapchat, considerando a dinâmica da vigilância e das relações de poder em sua interface com a problemática ética que the é própria.

Se por um lado o Facebook é uma rede aberta, onde tudo que é postado encontra-se passível de julgamento e vigilância social, o Snapchat por sua vez pode ser entendido como uma área de relativa "sombra" para este panóptico cibernético. Pelo fato 
do conteúdo desaparecer em pouco tempo, a vigilância social é limitada e os usuários se sentem mais livres das amarras da "netiqueta" e dos impactos de controle exercidos pelos diferentes atores dessa rede. Tal configuração traz consequências diversas. Por um lado, oferece mais espontaneidade e despreocupação nas manifestações e compartilhamento de informações, favorecendo ainda mais a exposição da intimidade e a sensação de liberdade. Por outro, oferece maior descompromisso com o impacto ou repercussão social dessas mesmas formas de manifestação, favorecendo a expressão de conteúdos que poderiam ser considerados inadequados pela "netiqueta", ou mesmo tomados como radicais, revolucionários ou ofensivos por determinados grupos sociais.

É comum que se considere a rede como um espaço de liberdade e que se exaltem suas vantagens de interação pessoal e profissional - que, sem dúvida, são muitas. Entretanto, nem sempre consideramos de forma crítica a dinâmica das relações de poder ali presentes, os mecanismos de vigilância, os modos de punição que se apresentam, muito menos consideramos como tudo isso promove a adequação de comportamentos e a produção de subjetividade. Uma melhor compreensão crítica desse cenário no qual estamos, cada vez mais, significativamente inseridos, pode contribuir para a reflexão sobre as possibilidades de "liberdade" oferecidas. Parece fundamental promover um olhar filosófico sobre o tema, buscando encontrar melhores condições para uma consideração crítica acerca da dinâmica que é própria às redes sociais. Como afirma Foucault (2005), é preciso compreender aquilo no que nos tornamos para que possamos pensar eticamente nas possibilidades de mudança que se fazem necessárias.

Sem dúvida, a tecnologia de informação avança de forma muito mais veloz do que nossa capacidade ordinária de refletir sobre qual seria nossa melhor forma de lidar com ela. Tal questão envolve enfrentar não somente a pergunta filosófica sobre quais ferramentas tecnológicas seriam mais interessantes aos nossos propósitos (Facebook, Snapchat etc.), mas principalmente significa perguntar qual seria nossa melhor forma de empregá-las, tendo em vista que estamos inexoravelmente inseridos em uma dinâmica de relações de poder. E seria um equívoco supor que somos simplesmente "vítimas" de tais relações. Não se pode perder de vista que todos nós exercemos poder continuamente (ao curtir, postar, compartilhar, manifestar emoticons etc.) e, ao fazê-lo, reforçamos ou combatemos certos discursos ou práticas presentes em nossa sociedade ou organização, como também investimos em certas configurações de subjetividade ou contribuímos para desconstruí-las. Desse modo, não há como escapar ao fato de que se colocam persistentemente questões éticas acerca do exercício de nossa liberdade nas redes sociais. Enfrentar a pergunta sobre qual a melhor maneira de exercer a liberdade em uma sociedade tecnológica apresenta-se como um dos mais importantes desafios da contemporaneidade.

Nesse sentido, sugere-se uma agenda de pesquisas futuras que aprofunde a discussão sobre as relações de poder e seus desdobramentos não só nas interações sociais, mas também seus efeitos na comunicação organizacional e nas práticas das relações públicas.

\section{REFERÊNCIAS}

BAUMAN, Zygmunt. Modernidade e ambivalência. Trad. de Marcus Antunes Penchel. Rio de Janeiro: Zahar, 1999. Modernidade líquida. Trad. de Plinio Augusto de Souza Dentzien. Rio de Janeiro: Zahar, 2001.

BAYER, Joseph B. et al. Sharing the small moments: ephemeral social interaction on Snapchat. Information, Communication \& Society, Abingdon, v. 19, n. 7, p. 956-977, 2016.

BELK, Russell W. Extended self in a digital world. Journal of Consumer Research, Chicago, v. 40, n. 3, p. 477-500, out. 2013. 
You are what you can access: sharing and collaborative consumption online. Journal of Business Research, Amsterdam, v. 67, n. 8, p. 1595-1600, ago. 2014.

BENTHAM, Jeremy. Panopticon, or, the inspection-house, \&c. In: Criminological perspectives: essential readings. 3. ed. v. 2. London: SAGE, 2003. p. 25-31.

CASTELLS, Manuel. A sociedade em rede. Trad. de Roneide Venâncio Majer. 8. ed. São Paulo: Paz e Terra, 1999. v. 1.

CHEVITARESE, Leandro; PEDRO, Rosa Maria L. R. Da sociedade disciplinar à sociedade de controle: a questão da liberdade por uma alegoria de Franz Kafka, em O Processo, e de Phillip Dick, em Minority Report. Estudos de Sociologia, Recife, v. 8, n. 1-2, p. 129-162, 2005.

DELEUZE, Gilles. Controle e devir. Entrevista por Toni Negri. In: Conversações. Trad. de Peter Pál Pelbart. São Paulo: 34, 1992a. p. 209-218.

Post-scriptum: sobre as sociedades de controle. In: Conversações. Trad. de Peter Pál Pelbart. São Paulo: 34, 1992b. p. 219-226.

FOUCAULT, Michel. História da sexualidade l: a vontade de saber. Trad. de Maria Thereza da Costa. Albuquerque e J. A. Guilhon Albuquerque. 13. ed. Rio de Janeiro: Graal, 1988.

Em defesa da sociedade. Trad. de Maria Ermantina Galvão. São Paulo: Martins Fontes, 1999.

Vigiar e punir. Trad. de Raquel Ramalhete. 25. ed. Petrópolis: Vozes, 2002.

0 que são as luzes? In: Ditos e escritos II. Rio de Janeiro: Forense Universitária, 2005. p. 335-351.

GOMES, Mayra R. Poder no jornalismo: discorrer, disciplinar, controlar. São Paulo: Edusp, 2003.

KOZINETS, Robert V. Utopian enterprise: articulating the meanings of Star Trek's culture of consumption. Journal of Consumer Research, Chicago, v. 28, n. 1, p. 67-88, jun. 2001.

KUNSCH, Margarida M. K. A função das Relações Públicas e a prática comunicacional nas organizações. Organicom, São Paulo, v. 1, n. 1, p. 124-139, ago. 2004.

Gestão das Relações Públicas na contemporaneidade e a sua institucionalização profissional e acadêmica no Brasil. Organicom, São Paulo, v. 3, n. 5, p. 30-61, 2. sem. 2006a.

Planejamento e gestão estratégica de relações públicas nas organizações contemporâneas. Anàlisi, Barcelona, n. 34, p. 125-139, 2006b.

KURTZ, João. Facebook domina ranking de redes sociais mais usadas no mundo. Techtudo, 30 jul. 2017. Disponível em: <https://goo.gl/5fyXLq> Acesso em: 6 mar. 2018.

MACÊDO, Ivanildo I. et al. Ética e sustentabilidade. Rio de Janeiro: Editora FGV, 2015. 
OLIVEIRA, Mauro J.; HUERTAS, Melby K. Z. A satisfação com a vida influencia a intenção de uso do Facebook? REMark-Revista Brasileira de Marketing, v. 13, n. 6, p. 124-137, out./dez. 2014.

TERRA, Carolina. As relações públicas e as novas tecnologias de informação e de comunicação. Caligrama, São Paulo, v. 1, n. 2, 2005. Não paginado.

TUBENCHLAK, Daniel B. et al. Motivações da comunicação boca a boca eletrônica positiva entre consumidores no Facebook. RAC, Rio de Janeiro, v. 19, n. 1, p. 107-126, jan./fev. 2015.

UTZ, Sonja; MUSCANELL, Nicole; KHALID, Cameran. Snapchat elicits more jealousy than Facebook: a comparison of Snapchat and Facebook use. Cyberpsychology, Behavior, and Social Networking, New Rochelle, v. 18, n. 3, p. 141-146, mar. 2015.

VATERLAUS, J. Mitchell et al. "Snapchat is more personal": an exploratory study on Snapchat behaviors and young adult interpersonal relationships. Computers in Human Behavior, Amsterdam, v. 62, p. 594-601, set. 2016.

VIANNA, lara. Social Media Trends 2018: panorama das empresas e usuários nas redes sociais. Inteligência RockContent, 6 dez. 2017. Disponível em: <https://goo.gl/7Q6tGq>. Acesso em: 6 mar. 2018.

Texto recebido em 21.11.2017 e aprovado em 21.11.2017. 